The psychological symptoms of anxiety were encountered in 57 (55.8\%) participants with IBS, among which, male were $15.7 \%$ and female $84.2 \%$ respectively.

Conclusion The medical students of Karachi who suffered more mental stress and anxiety resulted in a high level IBS as compared with previous study reports. There were significantly more women with IBS than men. As a consequence, key health messages and interventions to reduce stress and anxiety among students may help in curtailing the burden of this disease.

\section{SP4-11 METABOLIC PROFILE INFLUENCE ON HBA1C IN DIAGNOSING DIABETES MELLITUS}

doi:10.1136/jech.2011.142976p.5

T Dzebisashvili.* Moscow Regional Research Clinical Institute named by M.F.Vladimirskiy, Moscow, Russia

Aims To evaluate the optimum HbA1c cut-off for lowing number of people with undiagnosed type 2 diabetes mellitus (T2DM).

Materiales and Methods Population-based screening for glucose metabolism impairments (GMI) among 661 adults in Moscow Country was conducted in 2009. HbA1c was determined in 39 subjects with GMI. T2DM was diagnosed according to WHO 1999 criteria. Receiver operating characteristics (ROC) analysis was performed to assess best predictive cut-off HbA1c for diagnosing T2DM.

Results Based on OGTT and HbA1c, $15 \%$ and $28 \%$ people had T2DM. Area under ROC curve (AUROC) was 0,727 (95\% CI 0.490 to $0.964, p=0.080$, sensitivity $66.7 \%$, specificity $78.8 \%$ ) using $\mathrm{HbA1c}$ cut-off $>6.5 \%$. Best predictive HbA1c in this cohort was $6.3 \%$ (AUROC $0.750, p=0.054$, sensitivity $83 \%$, specificity $67 \%$ ). $33.0 \%$ of undiagnosed T2DM had HbA1c levels <6.5\% (95\% CI 0\% to $71 \%$ ) and $17 \%(95 \% \mathrm{Cl} 0 \%$ to $45 \%)$ of people with T2DM had $\mathrm{HbA} 1 \mathrm{c}$ levels $<6.3 \%$. Subjects with false negative $\mathrm{HbA1c}$ were predominantly with normal BMI $(21.8+1.6$ vs $42.9+7.8, p=0.025)$, false positives were predominantly with higher BMI $(30.6+7.8$ vs $28.4+$ $5.9, \mathrm{p}=0.273$ ). In normal weight (BMI 18-25) individuals optimal HbA1c cut-point for detecting T2DM was $>6.0 \%$ (AUROC 0.750 , sensitivity $50 \%$, specificity $100 \%$ ). RR of T2DM was 7 (1.18-42.9) with $\mathrm{HbA1c}$ values $6.0-6.4 \%$, than those with $<6.0$ in normal weight individuals.

Conclusion Choosing the HbA1c strategy rather than the OGTT strategy leads to diagnose more diabetes, although the consistency of both diagnostic criteria is low. The optimal HbA1c cut-point to detect T2DM was lower than HbA1c of $6.5 \%$ in normal weight individuals.

\section{SP4-12 HOW "HEALTHY" ARE THE CLIMATE CHANGE CONFERENCES?}

doi:10.1136/jech.2011.142976p.6

A M Z Hussain. * South East Asian Regional Office of World Health Organization, New Delhi, Iran

Since the first UN Conference on Human Environment held in Stockholm in 1972, up to COP16 numerous international conferences have been organised by UNEP, WMO, IPCC, AsDB/AfDB, UNDP, World Bank and of course UNFCCC. All of these prescribed economic development as the gateway to adaptation to and mitigation of emission of green house gases and global warming. Attention has been given to agriculture, fishery, topography, geography, land quality, tourism, livelihood, water resources management, waste management, forestry, environmental sanitation, public education, training, human resource development etc.; while health or disease were mentioned barely and episodically, to be forgotten in between. That health is the centre piece of development has not dawned upon. The drafters of resolutions and conference records, seems, never included any public health expert or epidemiologist. This has prompted Africa, South Asia, South East Asia, the Far East and the Pacific rim countries to request UNFCCC to accord due importance to health as a key element of adaptation to climate change. Based on a study of the relevant documents on climate change (referred to in the main paper), which evidently side tracked health as an issue of sufficient importance, we suggest that: (1) a monograph be produced by the UNFCCC on the remits and ranges of the impacts of climate change on health and disease; (2) due importance be given to health in the "negotiating document" of UNFCCC; and (3) public health experts and epidemiologist are included in the different committees of UNFCCC and GEF.

\section{SP4-13 DIFFERENCES IN CHILDREN'S AND ADULTS VULNERABILITY TO AIR AND WATER POLLUTION}

doi:10.1136/jech.2011.142976p.7

${ }^{1} \mathrm{R}$ Guimarães, ${ }^{*}{ }^{1} \mathrm{I}$ Braga, ${ }^{2} \mathrm{~J}$ Chrisman, ${ }^{1} \mathrm{C}$ Asmus. ${ }^{1}$ Federal University of Rio de Janeiro, Institute of Studies in Public Health, Rio de Janeiro, Brazil; ${ }^{2}$ Oswaldo Cruz Foundation, Rio de Janeiro, Brazil

Objective To discuss the differential susceptibility of children to environmental exposures using mortality rates for children and adults for infectious respiratory and gastrointestinal problems.

Materials and Methods We conducted an ecological study. We examined the trend in mortality rate from acute respiratory infections and acute diarrhoeal diseases and compared this with the consumption of chlorofluorocarbons-CFCs (air pollutant) and coverage of sewage services in Brazil. We used the polynomial regression model for assessment of trends, which were compared according to age categories with air pollution or water pollution proxy).

Results The consumption of CFCs was associated with increased mortality from the respiratory infection Agura. Increased sewage service coverage was associated with reduced mortality. This relationship was more pronounced in children than in adults.

Conclusion This new knowledge about children and susceptibility to environmental agents will help to identify subgroups and allow age sensitive planning of preventive actions.

\section{SP4-14 PASSIVE SMOKING IN BRAZIL: RESULTS FROM THE SPECIAL RESEARCH ON SMOKING 2008}

doi:10.1136/jech.2011.142976p.8

V Passos, ${ }^{*}$ L Giatti, S Barreto. Faculty of Medicine, Federal University of Minas Gerais, Belo Horizonte, Minas Gerais, Brazil

Introduction Passive smoking has been linked to an increased morbidmortality risk, mainly by cardiovascular and respiratory diseases. This is first Brazilian nationwide study that describes indoor passive smoking, at home and at work, among participants (15+ years) of the "Special Research on Smoking," a sub-sample of the PNAD2008, a representative national home survey.

Methods Non-smokers who reported exposure to indoor household smoking were classified as daily or occasional passive smokers, based on the frequency of exposure. People with indoor occupations, who were non-smoker and reported exposure to smoking during their work journey were classified as worksite passive smokers. Associations with socio-demographic factors were verified by logistic regression analysis. 
Results Among 25.005 participants, prevalence of daily and occasional household exposure was $12.5 \%$ and $21 \%$, respectively. Compared to non-exposed, daily household exposure decreased with increasing age, schooling and income. Occasional household exposure is not influenced by age, but decreases with increasing schooling and income. Compared to the Southeast Region, the most developed region in Brazil, daily exposure was lower in the North and Central West and higher in the Northeast. Among 10.933 participants with indoor occupations, $55 \%$ of men and $45 \%$ of women reported worksite exposure to passive smoking and $67 \%$ of them also reported household exposure. Prevalence of worksite exposure is higher in men, older adults (55+ years) and among participants with lower schooling and income and lower among South Region residents.

Conclusion Exposure to secondhand tobacco smoke, at home and at work, is very high and socially unequal in Brazil.

\section{SP4-15 BUILDING RESEARCH CAPACITY IN DEVELOPING COUNTRIES-COST EFFECTIVENESS OF AN EPIDEMIOLOGY COURSE TAUGHT BY TRADITIONAL AND VIDEO- TELECONFERENCING METHODS IN PAKISTAN}

doi:10.1136/jech.2011.142976p.9

${ }^{1} \mathrm{~S}$ Dodani, ${ }^{*} \mathrm{~T}$ Songer, ${ }^{2} \mathrm{R}$ LaPorte, ${ }^{3} \mathrm{Z}$ Ahmed. ${ }^{1}$ University of Kansas Medical center, Leawood, USA; ${ }^{2}$ University of Pittsburgh, Pittsburgh, USA; ${ }^{3}$ Unicom e-Health, Karachi, Pakistan

Building research capacity in developing countries using cost-effective methods has been recognised as an important pillar for the production of a sound evidence base for decision-making in policy and practice. We assessed the effectiveness of a research training course using traditional as well as video-teleconference method in Pakistan. A 9-day epidemiology research training course was offered to physicians in Pakistan (92\%) and Bangladeshis (8\%). The course was taught using (a) a traditional class room-face-to-face (F2F) method at the Aga Khan University, Karachi, Pakistan; and (b) Video Tele-Conferencing (VTC) method at two medical institutions within Pakistan. A total of 40 participants were selected for F2F and 46 for VTC group. Outcome parameters were assessed pre- and postcourse (short-term) as well as after 1 year (long-term). Costs of conducting the training in both methods were also identified using cost-effectiveness analysis.

Results The total study sample included 56 participants (F2F=38 and VTC=18) for the short-term and 49 participants for long-term assessment. After the end of the course (9th day), mean post-test1 scores showed significant improvement in both the groups that is, $15.08 \pm 1.75$ in F2F $(p=0.001)$ vs $13.122 \pm 1.87$ in VTC $(p=0.001)$ Mean scores after 1-year of the course (post-test 2) were lower than mean post-test 1 scores in both groups $(13.42 \pm 2.61$ in F2F vs $12.31 \pm 2.08$ in VTC), however, were higher than the baseline pretest scores.

Conclusion The use of e-technologies in developing countries proves to be an effective way of building capacity and reducing the problems of brain drain.

\section{SP4-16 DOES EDUCATION MODIFY THE ASSOCIATION BETWEEN SELF-RATED HEALTH AND MORTALITY AMONG OLDER PEOPLE IN INDONESIA?}

doi:10.1136/jech.2011.142976p.10
Reproductive Health, Faculty of Medicine, Gadjah Mada University, Yogyakarta, Indonesia

Introduction Evidences on whether poor self-reported health (SRH) predicts subsequent mortality across different socio-economic groups are inconsistent. This study assesses whether education modifies how poor SRH influences mortality among older people in Indonesia.

Methods A cohort of 11753 men and women aged 50 years and over was recruited in the INDEPTH/WHO Study on Adult Health and Global Ageing (SAGE) in Purworejo Health and Demographic Surveillance (HDSS) site in 2007. SRH was measured using the single global SRH question with 5-point response scales (very good, good, moderate $=$ moderately good SRH; bad, very bad=poor SRH) The baseline data were linked to the HDSS mortality data in 2010 HR for mortality was calculated for poor SRH using Cox proportional hazard regression after adjustment for age, education levels, age, marital status, living area, history of chronic diseases, and presence of disabilities.

Results During follow-up (median duration=37 months), 1199 deaths $(10.2 \%)$ and $1.9 \%$ lost to follow-up were identified. Poor SRH increased the mortality risk in men (HR 3.59, 95\% CI 1.96 to 6.57) and women (HR 3.16, 1.12 to 8.90). Education levels were not associated with mortality risk. The association between poor SRH and mortality did not differ across education groups, neither in men nor in women. Presence of disabilities, history of chronic diseases, and living alone increased the mortality risk.

Conclusion Poor SRH predicts mortality among older population in Indonesia. Education does not modify the association between poor $\mathrm{SRH}$ and mortality. Health promotion in the general population is important for the reduction of the mortality risk among older people.

\section{SP4-17 PREVALENCE OF HEPATITIS B AND C AMONG PREOPERATIVE CATARACT PATIENTS OF KARACHI}

doi:10.1136/jech.2011.142976p.11

E U Siddiqui, ${ }^{*}$ S S Naeem. Dow University of Health Sciences, Karachi, Sind, Pakistan

Introduction Hepatitis B and C are among the leading causes of morbidity and mortality, worldwide as well as in Pakistan. We intended to find out the prevalence of hepatitis B and C among preoperative cataract patients in Karachi. It is hypothesised that a high proportion of patients undergoing elective cataract surgery are infected with hepatitis B and C. Thus, it is imperative to come up with frequency to design strategies to decrease the burden.

Methods A descriptive study was conducted among 240 patients presenting for cataract surgery to Civil Hospital, Karachi. Diagnosis were made on the criteria that a patient must be positive for either $\mathrm{HBsAg}$ or Anti-HCV, or both. Convenience sampling was done after getting written informed consent.

Results Overall, five out of 235 (2.13\%) patients were HBsAg positive and 29 out of 239 (12.13\%) were Anti-HCV positive. One patient had a co-infection with both HBsAg and Anti-HCV positive. Conclusion High proportion of Hepatitis B and C are reported among preoperative cataract patients of Karachi. Routine serological screening prior to surgery should be made mandatory so that standard precautions could be taken and asymptomatic carrier patients would no longer pose a threat to its spread.

\section{SP4-18 A NEED ASSESSMENT STUDY OF HIV VOLUNTARY COUNSELLING AND TESTING SERVICES IN BANGLADESH}

doi:10.1136/jech.2011.142976p.12

\section{S S Chowdhury, ${ }^{*}$ U Kulsum, S H Talukder. Eminence, Dhaka, Bangladesh}

Backgrounds VCT is considered as an entry point for prevention and care and is acknowledged internationally as an effective strategy for 